\title{
Associations between TG/HDL ratio and insulin resistance in the US population: a cross-sectional study
}

\author{
Rongpeng Gong ${ }^{1}{ }^{1, *}$, Gang Luo ${ }^{2, *}$, Mingxiang Wang ${ }^{1}$, Lingbo Ma ${ }^{1}$, Shengnan Sun ${ }^{1}$ and Xiaoxing Wei ${ }^{1}$ \\ ${ }^{1}$ Medical College, Qinghai University, Xining, People's Republic of China \\ ${ }^{2}$ College of Eco-Environmental Engineering, Qinghai University, Xining, People's Republic of China \\ Correspondence should be addressed to S Sun or X Wei: sunsn@qhu.edu.cn or weixiaoxing@tsinghua.org.cn \\ *(R Gong and G Luo contributed equally to this work)
}

\begin{abstract}
Background: Clinical data on the relationship between triglycerides (TG)/HDL ratio and insulin resistance (IR) suggest that TG/HDL ratio may be a risk factor for IR. However, there is evidence that different races have different risk of developing IR. The relationship on TG/HDL ratio and IR in various populations needs to be improved. Therefore, we investigated whether TG/HDL ratio was linked to IR in different groups in the United States after controlling for other covariates.

Methods: The current research was conducted in a cross-sectional manner. From 2009 to 2018, the National Health and Nutrition Examination Survey (NHANES) had a total of 49,696 participants, all of whom were Americans. The target-independent variable was TG/HDL ratio measured at baseline, and the dependent variable was IR. Additionally, the $\mathrm{BMI}$, waist circumference, education, race, smoking, alcohol use, alanine transaminase, aspartate transaminase, and other covariates were also included in this analysis.

Results: The average age of the 10,132 participants was $48.6 \pm 18.4$ years, and

approximately 4936 (48.7\%) were males. After correcting for confounders, fully adjusted logistic regression revealed that TG/HDL ratio was correlated with IR (odds ratio $=1.51$, $95 \% \mathrm{Cl}$ 1.42-1.59). A nonlinear interaction between TG/HDL ratio and IR was discovered, with a point of 1.06. The impact sizes and $\mathrm{Cls}$ on the left and right sides of the inflection point were 6.28 (4.66-8.45) and 1.69 (1.45-1.97), respectively. According to subgroup analysis, the correlation was strong in females, alcohol users, and diabetes patients. Meanwhile, the inverse pattern was observed in the aged, obese, high-income, and smoking populations.

Conclusion: In the American population, the TG/HDL ratio is positively associated with IR in a nonlinear interaction pattern.
\end{abstract}

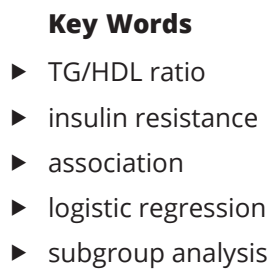

Endocrine Connections (2021) 10, 1502-1512

\section{Background}

Insulin resistance (IR) is the insensitivity to insulin in insulin-dependent organs and tissues (1). The clinical manifestation of IR is the failure to respond to increase in blood sugar, which is associated with metabolic disorders of fat, protein, and carbohydrate storage in the body
(2). The development of obesity usually accompanies IR (3). Moreover, IR is a key pathological driver of the development of type 2 diabetes and cardiovascular disease $(4,5,6,7,8)$, and the presence of IR has been linked to metabolic disturbances in several studies (9).

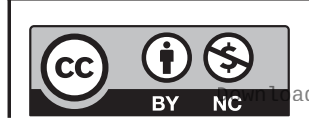

This work is licensed under a Creative Commons Attribution-NonCommercial 4.0 International License. ded from Bioscientifica.com at 04/26/2023 10:03:49AM 
Furthermore, IR is most likely to intensify those conditions and increase death rate from all causes $(10,11$, 12). Welsh et al. found that older adults without IR had a much lower incidence of diabetes than those with IR (13). Another 13-year follow-up study showed that patients with IR also had a considerably increased risk of cardiovascular disease (14). Perseghin et al. conducted a 15 -year cohort study and concluded a 5.6\% higher mortality rate of cancer patients with IR relative to non-IR cancer cases (15). Therefore, it is highly desirable to prevent the occurrence of IR for patient survival and public health (16).

Many causes, such as smoking, alcohol, hyperlipidemia, and hypertension, have been identified as risk factors for developing IR. Since these causes are common in modern life, we expect IR to become increasingly common in the general population unless public awareness is increased (17).

There are currently a variety of approaches for making a primary diagnosis of IR, either directly or indirectly (18). The gold standard for diagnosing IR is the hyperinsulinemic-euglycemic clamp test, which was initially developed by DeFronzo et al. (19). Unfortunately, this strategy has a number of drawbacks due to its high cost, time requirements, and invasiveness. As a result, this procedure is unsuitable for clinical use, especially when assessing a large number of samples (20). It is necessary to study the effective method in clinical prediction of IR, and correlative factors need to be found.

Triglycerides (TG) and HDL have been shown to be important factors in the formation of IR $(21,22)$. An increase in TG was shown to be a risk factor for the development of IR, while an increase in HDL was considered a protective factor. Many scholars have used the ratio of the two to investigate the relationship of both factors with IR. The TG/HDL ratio was found to be more closely linked to the development of IR than either TG or HDL alone. Notably, studies indicate that the TG/HDL ratio is a straightforward quantifiable measurement of IR and a marker of diabetes and coronary heart disease $(23,24)$.

However, results from previous studies on the relationship between TG/HDL ratio and IR suggest that more investigation is needed, especially since the sample sizes were small $(25,26)$. It should be noted that the conditions for the development of IR vary among populations. Therefore, more research is needed to understand the differences in study design, target population, and data processing. In this study, we used data from the National Health and Nutrition Examination Survey (NHANES) to investigate whether the TG/HDL ratio was linked to IR in adults in the United States.

\section{Participants and methods}

\section{Study design}

This was a cross-sectional study. The target-independent and outcome variable was the TG/HDL ratio and IR, respectively. All indicators of each sample were detected at the same time and collected by the NHANES database. The total population was divided into two groups according to the outcome, IR positive and IR negative group.

\section{Study population}

The data for this study were derived from the NHANES cross-sectional study by the Centers for Disease Control (CDC) and Prevention National Center for Health Statistics (NCHS; http://www.cdc.gov/nchs/nhanes/). The sample source of NHANES was based on a complex, stratified, multi-stage design with a resident sample derived from a nationally representative population sample $(17,27)$. The NHANES program began in the early 1960s as a series of surveys of different populations or health topics. The NHANES study program is described in detail at the website of CDC. The NHANES protocol has been revised and approved by the NCHS Research Ethics Committee. All participants provided written informed consent before participation. The survey consists of a combination of interviews and medical examinations.

The study ensured that the results were representative of the American population, and we selected data from five NHANES cycles over 10 years (2009-2018). A total of 49,696 participants were enrolled in the survey over five cycles. The inclusion criteria were as follows: (1) at least 18 years old; (2) fasting blood glucose and insulin were measured; and (3) biochemical indexes such as TG and HDL were measured. Exclusion criteria included were (1) acute complications (diabetic ketoacidosis, diabetic hypersomnic coma, or lactic acidosis); (2) combined liver, biliary, and renal diseases or diseases affecting calcium and phosphorus metabolism; (3) patients taking any drugs for blood lipid metabolism and patients with abnormal secretion of thyroid and parathyroid hormones; (4) patients with infectious diseases, immune diseases, and malignant tumors; (5) history of osteoporosis or other diseases characterized by abnormal bone metabolism; (6) recent history of surgery, trauma, severe infection, or other severe stress; and (7) patients with mental illness. Finally, a total of 10,132 participants were enrolled in the study. There is no significant statistical difference of sample sensitivity between the selected and excluded groups.

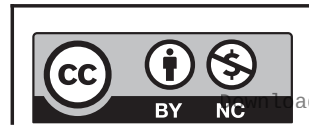

This work is licensed under a Creative Commons Attribution-NonCommercial 4.0 International License. ded from Bioscientifica.com at 04/26/2023 10:03:49AM 


\section{Variables}

The TG/HDL ratio was measured at the start of the study and followed as a constant variable. Blood samples from the patients were frozen at $-30^{\circ} \mathrm{C}$ and sent to the University of Minnesota for processing. In all tests, each stage of specimen reception, transport, and examination was defined. The tests were on a random subset comprising $2 \%$ of the sample, and NHANES used a lot of approaches to ensure that the results were accurate. Detailed analysis methods can be accessed on the NHANES website (https:// www.cdc.gov/nchs/nhanes/index.htm).

According to the published guidelines, HOMA-IR was calculated as the fasting glucose-insulin $(\mu \mathrm{U} / \mathrm{mL}) \times$ fasting glucose $(\mathrm{mmol} / \mathrm{L}) / 22.5$ (28). In a study of HOMA-IR in American adults, IR was considered to have occurred when the HOMA-IR index was higher than or equal to 2.73 (29), and no IR was thought to have occurred when the HOMA-IR index was lower than $2.73(29,30,31)$. Accordingly, IR was defined as HOMA-IR $\geq 2.73$ in this study.

In this study, we selected potential covariates as follows: (1) demographic data, (2) variables that were previously reported to affect TG/HDL ratio or IR, (3) introducing covariance resulted in a change of more than $10 \%$ in the regression coefficient of the basic model, and (4) other variables based on our clinical experience. Therefore, the following variables were used to construct the fully adjusted model: (1) continuous variables: age, BMI, waist circumference (WC), alanine transaminase (ALT), aspartate transaminase (AST), urea nitrogen (BUN), $\gamma$-glutamyl transpeptidase (GGT), lactate dehydrogenase (LDH), and vitamin D3 (VD3) (obtained at baseline); (2) categorical variables: gender, race, education, income, smoking, alcohol use, diabetes, hypertension, and hyperuricemia.

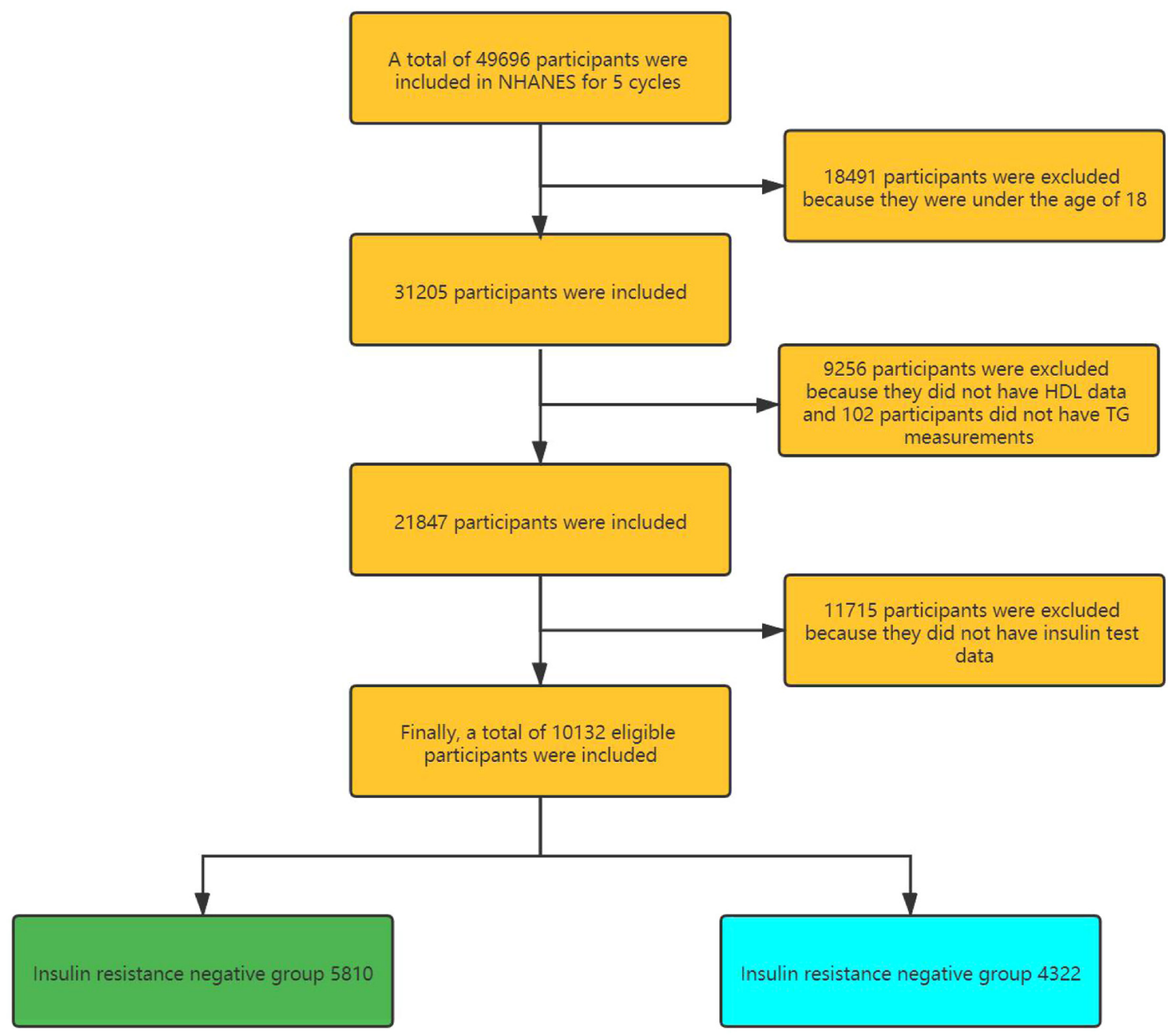

Figure 1

Flowchart of participant selection.

https://ec.bioscientifica.com https://doi.org/10.1530/EC-21-0414 (c) 2021 The authors Published by Bioscientifica Ltd

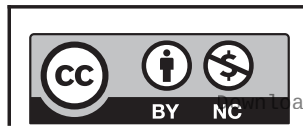

This work is licensed under a Creative Commons Attribution-NonCommercial 4.0 International License. ded from Bioscientifica.com at 04/26/2023 10:03:49AM via free access 
Table 1 Descriptive characteristics of the study participants.

\begin{tabular}{l} 
Variables \\
\hline Sex, $n$ (\%) \\
Male \\
Female \\
Age, mean \pm SD \\
Race, $n$ (\%) \\
Mexican American \\
Other Hispanics \\
Non-Hispanic White \\
Non-Hispanic Black \\
Other race \\
BMI, mean \pm SD \\
WC, mean \pm SD \\
Smoking, $n$ (\%) \\
No \\
Yes \\
Alcohol use, $n$ (ng\%) \\
No \\
Yes \\
Diabetes, $n$ (\%) \\
No \\
Yes \\
Education, $n(\%)$ \\
No higher education \\
Received higher education \\
Income, $n$ (\%) \\
No more than $\$ 100,000$ \\
More than $\$ 100,000$ \\
Hypertension, $n(\%)$ \\
No \\
Yes \\
ALT, median (IQR) \\
AST, median (IQR) \\
BUN, median (IQR) \\
GGT, median (IQR) \\
LDH, median (IQR) \\
VD3, median (IQR) \\
TG, median (IQR) \\
HDL, median (IQR) \\
TG/HDL, median (IQR) \\
\hline
\end{tabular}

\begin{tabular}{|c|c|}
\hline Total $(n=10,132)$ & IR-negative $(n=5810)$ \\
\hline 4936 (48.7) & 2772 (47.7) \\
\hline $5196(51.3)$ & 3038 (52.3) \\
\hline $48.6 \pm 18.4$ & $47.0 \pm 18.7$ \\
\hline 1407 (13.9) & $673(11.6)$ \\
\hline 1077 (10.6) & $558(9.6)$ \\
\hline 3809 (37.6) & 2296 (39.5) \\
\hline $2172(21.4)$ & $1228(21.1)$ \\
\hline 1667 (16.5) & 1055 (18.2) \\
\hline $29.1 \pm 7.1$ & $26.2 \pm 5.3$ \\
\hline $99.1 \pm 17.0$ & $91.8 \pm 13.4$ \\
\hline $5896(58.2)$ & 3420 (58.9) \\
\hline $4236(41.8)$ & $2390(41.1)$ \\
\hline $6591(65.1)$ & 3737 (67.3) \\
\hline 3541 (34.9) & $1814(32.7)$ \\
\hline $8519(84.1)$ & $5392(92.8)$ \\
\hline $1613(15.9)$ & $418(7.2)$ \\
\hline 1615 (15.9) & $390(7)$ \\
\hline $4488(44.3)$ & $2428(41.8)$ \\
\hline $5644(55.7)$ & $3382(58.2)$ \\
\hline $6557(64.7)$ & 3621 (62.3) \\
\hline 3575 (35.3) & 2189 (37.7) \\
\hline 4809 (47.5) & 3268 (56.2) \\
\hline $5323(52.5)$ & $2542(43.8)$ \\
\hline $20.0(15.0,27.0)$ & $18.0(14.0,24.0)$ \\
\hline $22.0(18.0,26.0)$ & $21.0(18.0,26.0)$ \\
\hline $4.6(3.6,5.7)$ & $4.6(3.6,5.7)$ \\
\hline $19.0(14.0,29.0)$ & $17.0(12.0,25.0)$ \\
\hline $130.0(113.0,150.0)$ & $128.0(112.0,149.0)$ \\
\hline $48.0(29.1,64.6)$ & $50.5(31.2,68.3)$ \\
\hline $1.2(0.8,1.7)$ & $1.0(0.7,1.4)$ \\
\hline $1.3(1.1,1.6)$ & $1.4(1.2,1.8)$ \\
\hline $0.9(0.5,1.4)$ & $0.7(0.4,1.1)$ \\
\hline
\end{tabular}

\begin{tabular}{|c|c|}
\hline IR-positive $(n=4322)$ & $P$ value \\
\hline & 0.02 \\
\hline \multicolumn{2}{|l|}{$2164(50.1)$} \\
\hline \multicolumn{2}{|l|}{$2158(49.9)$} \\
\hline \multirow[t]{2}{*}{$50.7 \pm 17.9$} & $<0.001$ \\
\hline & $<0.001$ \\
\hline \multicolumn{2}{|l|}{734 (17) } \\
\hline \multicolumn{2}{|l|}{$519(12)$} \\
\hline \multicolumn{2}{|l|}{$1513(35)$} \\
\hline \multicolumn{2}{|l|}{$944(21.8)$} \\
\hline \multicolumn{2}{|l|}{612 (14.2) } \\
\hline $33.0 \pm 7.4$ & $<0.001$ \\
\hline \multirow{2}{*}{$109.0 \pm 16.2$} & $<0.001$ \\
\hline & 0.116 \\
\hline \multicolumn{2}{|l|}{$2476(57.3)$} \\
\hline \multicolumn{2}{|l|}{1846 (42.7) } \\
\hline & $<0.001$ \\
\hline \multicolumn{2}{|l|}{2854 (62.3) } \\
\hline \multicolumn{2}{|l|}{$1727(37.7)$} \\
\hline & $<0.001$ \\
\hline \multicolumn{2}{|l|}{$3127(72.4)$} \\
\hline \multicolumn{2}{|l|}{1195 (27.6) } \\
\hline $1225(26.7)$ & $<0.001$ \\
\hline \multicolumn{2}{|l|}{2060 (47.7) } \\
\hline \multicolumn{2}{|l|}{$2262(52.3)$} \\
\hline & $<0.001$ \\
\hline \multicolumn{2}{|l|}{$2936(679)$} \\
\hline \multicolumn{2}{|l|}{$1386(32.1)$} \\
\hline \multirow{2}{*}{\multicolumn{2}{|c|}{1541 (35.7) }} \\
\hline & \\
\hline \multicolumn{2}{|l|}{$2781(64.3)$} \\
\hline $23.0(17.0,32.0)$ & $<0.001$ \\
\hline $22.0(18.0,28.0)$ & $<0.001$ \\
\hline $4.6(3.6,6.1)$ & $<0.001$ \\
\hline $23.0(17.0,35.0)$ & $<0.001$ \\
\hline $131.0(115.0,152.0)$ & $<0.001$ \\
\hline $44.8(26.6,60.2)$ & $<0.001$ \\
\hline $1.5(1.0,2.1)$ & $<0.001$ \\
\hline $1.2(1.0,1.4)$ & $<0.001$ \\
\hline $1.2(0.8,2.0)$ & $<0.001$ \\
\hline
\end{tabular}

ALB, albumin; ALP, alkaline phosphatase; ALT, alanine transaminase; AST, aspartate aminotransferase; BUN, urea nitrogen; GGT, $\gamma$-glutamyl transpeptidase; FPG, fasting plasma glucose; IR, insulin resistance; LDH, lactate dehydrogenase; TG, triacylglycerol; UA, uric acid; WC, waist circumference; VD3, vitamin D3 (cholecalciferol).

\section{Covariate definitions}

\section{Education}

The study population was divided into (1) participants who received a college education or above and (2) participants who have not received a junior college degree or above.

\section{Income}

Based on the American Average Income Report, we defined participants in this study as high income with a household income of more than $\$ 100,000$ per year and low income with less than $\$ 100,000$ per year.

\section{Smoking}

We divided the participants into three groups depending on their smoking status: (1) current smokers: smoked more than one cigarette per day within the past 30 days; (2) current nonsmokers: smoked less than one cigarette per day on average within the past 30 days or smoked more than 100 cigarettes in total over their lifetime; and (3) nonsmokers: smoked less than 100 cigarettes in total over their lifetime or never smoked. In this study, because the number of nonsmokers was too small, we finally defined the population as current nonsmokers as nonsmokers (27).

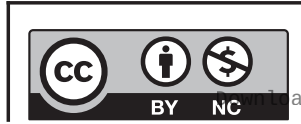

This work is licensed under a Creative Commons Attribution-NonCommercial 4.0 International License. ded from Bioscientifica.com at 04/26/2023 10:03:49AM via free access 


\section{Alcohol use}

We looked at the classification of alcohol consumption in previous studies and classified alcohol consumption into drinkers, those who consume more than 12 drinks a year; and nondrinkers, those who do not drink more than 12 drinks a year $(32,33)$.

\section{Diabetes mellitus}

The 2015 American Diabetes Association criteria were used as the basis for the definition of diabetes. In this study, we defined diabetic patients as a population of participants with self-reported diabetes, those taking medication for diabetes, HbAlc $\geq 6.5$, fasting glucose $\geq 7.0$, based on questionnaires and laboratory tests (34).

\section{Hypertension}

In this study, we averaged the blood pressure values based on the participants' three measurements in the resting state and used the mean to determine whether the participants had hypertension. Hypertension was diagnosed based on systolic blood pressure $\geq 140 \mathrm{mmHg}$ or diastolic blood pressure $\geq 90 \mathrm{mmHg}$ or those who self-reported having hypertension or were taking antihypertensive drugs (33, 35). This definition is consistent with the 2017 American Heart Association blood pressure guidelines.

\section{Hyperuricemia}

Through multiplying the measured value by 59.48 , the unit was converted from $\mathrm{mg} / \mathrm{dL}$ to $\mu \mathrm{mol} / \mathrm{L}$. According to the literature, the hyperuricemia is diagnosed as a level of uric acid higher than $420 \mu \mathrm{mol} / \mathrm{L}$ in men or higher than $360 \mu \mathrm{mol} / \mathrm{L}$ in women.

\section{Statistical analyses}

Categorical variables were expressed as frequencies or percentages. We used the $\chi^{2}$ test (categorical variables), means, and 95\% CIs (normal distribution), or median and Q1-Q3 (skewed distribution) to test for differences between distinct IR-positive and IR-negative groups. Based on previous studies, participants with HOMA-IR $\geq 2.73$ (30) were defined as the IR-positive group, while those with HOMA-IR $<2.73$ were defined as the IR-negative group. Step 1: Univariate and multivariate logistics regression was employed. We constructed four models: model 1 , no covariates were adjusted; model 2 , only adjusted for sociodemographic factors; model 3, model 2+ BMI, WC, smoking, alcohol use, education, and income; model 4, model 3+ other covariates. Step 2: To address the nonlinearity of TG/HDL ratio and IR, logistic regression and smoothed curve fitting (penalized spline method) were conducted. If nonlinearity was detected, we first calculated the inflection point using a recursive algorithm and then constructed a two-part logistic regression on both sides of the inflection point of the logistic regression. Step 3: Subgroup analyses were performed using stratified logistic regression models. Continuous variables were first converted into categorical variables according to

Table 2 Univariate analysis for IR.

\begin{tabular}{|c|c|c|}
\hline Variables & OR $(95 \% \mathrm{Cl})$ & $P$ value \\
\hline Age & $1.01(1.01-1.01)$ & $<0.001$ \\
\hline \multicolumn{3}{|l|}{ Gender } \\
\hline Male & 1 & 0.019 \\
\hline Female & $0.92(0.85-0.99)$ & \\
\hline \multicolumn{3}{|l|}{ Race } \\
\hline Mexican American & 1 & \\
\hline Other Hispanics & $0.85(0.73-1)$ & 0.049 \\
\hline Non-Hispanic White & $0.6(0.53-0.68)$ & $<0.001$ \\
\hline Non-Hispanic Black & $0.7(0.62-0.81)$ & $<0.001$ \\
\hline Other race & $0.53(0.46-0.61)$ & $<0.001$ \\
\hline $\mathrm{BMI}$ & $1.20(1.19-1.21)$ & $<0.001$ \\
\hline WC & $1.08(1.08-1.09)$ & $<0.001$ \\
\hline TG & $2.15(2.03-2.27)$ & $<0.001$ \\
\hline HDL & $0.13(0.12-0.15)$ & $<0.001$ \\
\hline TG/HDL & $2.12(2.01-2.24)$ & $<0.001$ \\
\hline $\mathrm{ALT}$ & $1.03(1.02-1.03)$ & $<0.001$ \\
\hline AST & $1.00(1.00-1.01)$ & 0.002 \\
\hline BUN & $1.06(1.04-1.08)$ & $<0.001$ \\
\hline VD3 & $0.99(0.99-0.99)$ & $<0.001$ \\
\hline \multicolumn{3}{|l|}{ Hypertension } \\
\hline No & 1 & \\
\hline Yes & $2.32(2.14-2.52)$ & $<0.001$ \\
\hline \multicolumn{3}{|l|}{ Smoking } \\
\hline No & 1 & \\
\hline Yes & 1.07 (0.99-1.16) & 0.112 \\
\hline \multicolumn{3}{|l|}{ Alcohol use } \\
\hline No & 1 & \\
\hline Yes & $1.25(1.15-1.35)$ & $<0.001$ \\
\hline \multicolumn{3}{|l|}{ Diabetes } \\
\hline No & 1 & \\
\hline Yes & $4.93(4.37-5.56)$ & $<0.001$ \\
\hline \multicolumn{3}{|l|}{ Education } \\
\hline No higher education & 1 & \\
\hline $\begin{array}{l}\text { Received higher } \\
\text { education }\end{array}$ & $0.79(0.73-0.85)$ & $<0.001$ \\
\hline \multicolumn{3}{|l|}{ Income } \\
\hline No more than $\$ 100,000$ & 1 & \\
\hline More than $\$ 100,000$ & $0.78(0.72-0.85)$ & $<0.001$ \\
\hline
\end{tabular}

ALT, alanine transaminase; AST, aspartate transaminase; BUN, urea nitrogen; FPG, fasting plasma glucose; GGT, $\gamma$-glutamyl transpeptidase; IR, insulin resistance; TG, triglyceride; UA, uric acid; VD3, vitamin D3 (cholecalciferol).

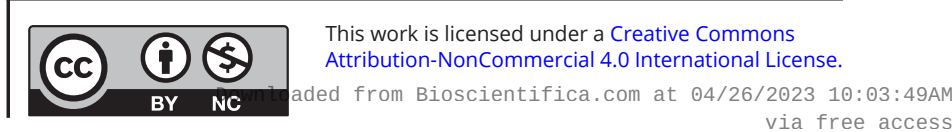


Table 3 The association between the TG/HDL ratio and IR in multiple logistic regression models. The data represent ORs and 95\% Cls. Model 1, non-adjusted; model 2, adjusted for age, gender, and race; model 3, adjusted for model $2+$ BMI, WC, education, income, diabetes, and hypertension; model 4, adjusted for model $3+$ ALT, AST, BUN, LDH, GGT, and VD3.

\begin{tabular}{|c|c|c|c|c|c|c|c|c|}
\hline \multirow[b]{2}{*}{ Variable } & \multicolumn{2}{|l|}{ Model 1} & \multicolumn{2}{|l|}{ Model 2} & \multicolumn{2}{|l|}{ Model 3} & \multicolumn{2}{|c|}{ Model 4} \\
\hline & OR $(95 \% \mathrm{Cl})$ & $P$ value & OR $(95 \% \mathrm{Cl})$ & $P$ value & OR $(95 \% \mathrm{Cl})$ & $P$ value & OR $(95 \% \mathrm{Cl})$ & $P$ value \\
\hline $\mathrm{TG} / \mathrm{HDL}$ & $2.12(2.01-2.24)$ & $<0.001$ & $2.18(2.06-2.31)$ & $<0.001$ & $1.56(1.48-1.65)$ & $<0.001$ & 1.51 (1.42-1.59) & $<0.001$ \\
\hline \multicolumn{9}{|l|}{ TG/HDL group } \\
\hline TG/HDL < 1.10 & 1 & & 1 & & 1 & & 1 & \\
\hline $\mathrm{TG} / \mathrm{HDL} \geq 1.10$ & $4.16(3.82-4.53)$ & $<0.001$ & $4.39(4.01-4.8)$ & $<0.001$ & $2.69(2.43-2.98)$ & $<0.001$ & $2.50(2.25-2.77)$ & $<0.001$ \\
\hline
\end{tabular}

the clinical cutoff, followed by an interactive test. The likelihood ratio test followed tests for effect modification for subgroup indicators. To ensure the robustness of the data analysis, we did a sensitivity analysis. We converted the TG/HDL ratio into a categorical variable and calculated the $P$ value for trend. The purpose was to test the results of TG/HDL ratio as a continuous variable and observe the possibility of nonlinearity. All the analyses were conducted using the statistical software package R 4.0.2 (R Foundation for Statistical Computing, Vienna, Austria). A two-tailed test was performed, and differences with $P<0.05$ (two-sided) were considered statistically significant.

\section{Results}

\section{Base characteristics of enrolled participants}

A total of 10,132 participants were selected for final data analysis (see flow chart in Fig. 1). The characteristics of the selected participants are listed in Table 1. The IR-positive and IR-negative groups were divided according to HOMA-IR 2.73 as the cutoff value (30).

The average age of the 10,132 selected participants was $48.6 \pm 18.4$ years, and $48.7 \%$ were male. The variables we selected were statistically significant in both groups (all $P<0.05)$. Participants from the IR-positive group had higher values of age, BMI, WC, TG, ALT, AST, GGT, and LDH than those in the IR-negative group. Additionally, the IR-positive group contained more participants who were smoking, use alcohol, or had hypertension and hyperuricemia than the IR-negative group. The opposite patterns were observed for VD3, HDL, education, and income.

\section{Univariate analyses}

The results of univariate analysis are presented in Table 2. Univariate logistic regression indicated that race, BMI, TG, HDL, hypertension, smoking, alcohol use, VD3, diabetes, education, and income were significantly associated with IR. We also concluded that education, income, VD3, and HDL were negatively associated with IR. By contrast, the univariate logistic regression showed that BMI, TG, hypertension, smoking, alcohol use, and diabetes were positively correlated with IR.

\section{Results of unadjusted and adjusted regression model}

In this study, we constructed four logistic models to analyze the independent effects of TG/HDL ratio on IR (univariate and multivariate logistic regression). The effect sizes of odds ratios (ORs) and 95\% CIs are shown in Table 3. The model-based effect value indicated the probability of IR increased for each addition of TG/HDL ratio. For example, the effect size of 2.12 for IR in the unadjusted model means a $112 \%$ increased risk of IR (OR 2.12; 95\% CI 2.01-2.24) with each 0.1 increased TG/HDL ratio. In the model only adjusted for sociodemographic data (model 2), with each $0.1 \mathrm{TG} / \mathrm{HDL}$ ratio increase, the risk of IR increased $118 \%$ (OR 2.18; 95\% CI 2.06-2.31). In model 3, with each 0.1 TG/HDL ratio increase, the risk of IR increased $56 \%$ (OR 1.56; 95\% CI 1.48-1.65). In the fully adjusted model (model 4), with each 0.1 TG/HDL ratio increase, the risk of IR increased 51\% (OR 1.51; 95\% CI 1.42-1.59).

Meanwhile, four linear regression models were constructed to analyze the association between TG/HDL

Table 4 The association between the TG/HDL ratio and IR in multiple linear regression models. The data represent ORs and 95\% Cls. model 1, non-adjusted; model 2, adjusted for age, gender, and race; model 3, adjusted for model 2 + BMI, WC, education, income, diabetes, hypertension, and hypercholesterolemia; model 4, adjusted for model $3+$ ALT, AST, BUN, LDH, GGT, and VD3.

\begin{tabular}{|c|c|c|}
\hline \multirow[b]{2}{*}{ Variable } & \multicolumn{2}{|c|}{ Model 1} \\
\hline & $\beta(95 \% \mathrm{Cl})$ & $P$ value \\
\hline TG/HDL & $0.81(0.72-0.89)$ & $<0.001$ \\
\hline
\end{tabular}

https://ec.bioscientifica.com https://doi.org/10.1530/EC-21-0414

$\frac{\text { Model } 2}{\frac{\beta(95 \% \mathrm{Cl})}{0.81(0.72-0.9)} \frac{P \text { value }}{<0.001}}$

(c) 2021 The authors Published by Bioscientifica Ltd

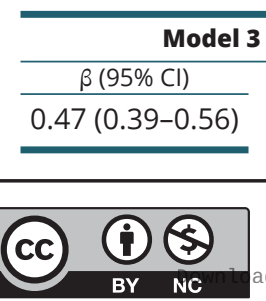

This work is licensed under a Creative Commons Attribution-NonCommercial 4.0 International License. ded from Bioscientifica.com at 04/26/2023 10:03:49AM 
ratio and IR when IR was regarded as a continuous variable (Table 4). The effect sizes of $\beta$ s and 95\% CIs showed that with each TG/HDL ratio increase, the $\beta$ value of HOMA-IR increased. For fully adjusted model (Model 4), the value of HOMA-IR increased 0.43 as TG/HDL ratio increased each 0.1

For sensitivity analysis, we converted TG/HDL ratio from a continuous variable to a categorical variable. The $P$ value for the trend of TG/HDL ratio with a categorical variable in a fully adjusted model was consistent with the result obtained using TG/HDL ratio as a continuous variable. Additionally, we also found that the tendency of the effect size in different TG/HDL ratio groups was isometric.

\section{Nonlinearity of TG/HDL ratio and IR}

In this study, we analyzed the nonlinear relationship between the TG/HDL ratio and IR (Fig. 2). Curve analysis and the results of logistic regression showed that the relationship between the TG/HDL ratio and IR was nonlinear after adjusting for age, race, BMI, WC, TC, ALT, AST, education, income, smoking, alcohol use, and

Table 5 Threshold effect analysis of TG/HDL ratio on incidence of IR in the NHANES study, 2009-2018. Adjusted for age, gender, race, BMI, WC, smoking, alcohol use, diabetes, hypertension, hypercholesterolemia, education, income, ALT, AST, BUN, GGT, LDH, and VD3.

Outcome

Break point

Two-part logistic

regression model

$\mathrm{TG} / \mathrm{HDL}<1.06$

$\mathrm{TG} / \mathrm{HDL} \geq 1.06$

Likelihood ratio test

Nonlinearity test

\begin{tabular}{ccc}
\hline OR $(95 \% \mathrm{Cl})$ & & P value \\
\hline $1.06(1.04-1.08)$ & & $<0.001$ \\
$6.278(4.663-8.452)$ & & $<0.001$ \\
$1.69(1.448-1.973)$ & & $<0.001$ \\
$<0.001$ & & \\
$<0.001$ &
\end{tabular}

hypertension. We used both logistic regression and twopart logistic regression to fit the association and select the best-fitting model based on the log-likelihood ratio test.

Because the $P$ value of the log-likelihood ratio test was less than 0.05, we chose two-part logistic regression to fit the association between TG/HDL ratio and IR because it can accurately represent the relationship. The two-part logistic regression and recursive algorithm indicated that the inflection point was 1.06. On the left side of the

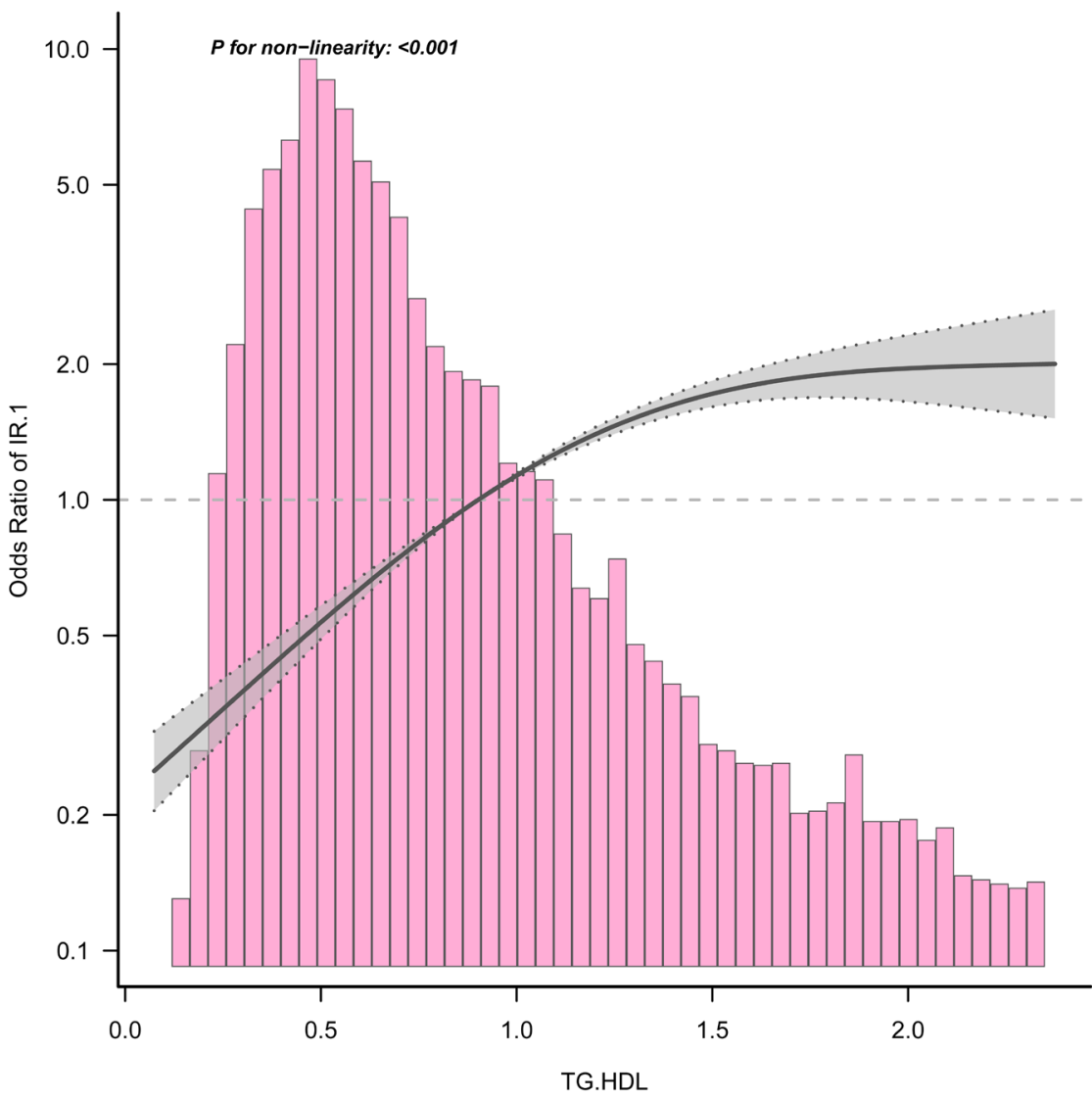

Figure 2

Multifactor logistic regression analysis of the association between the TG/HDL ratio and IR. https://ec.bioscientifica.com https://doi.org/10.1530/EC-21-0414 (c) 2021 The authors Published by Bioscientifica Ltd
This work is licensed under a Creative Commons Attribution-NonCommercial 4.0 International License. ded from Bioscientifica.com at 04/26/2023 10:03:49AM via free access 


\begin{tabular}{|c|c|c|c|c|c|c|}
\hline Subgroup & Variable & n.total & n.event_\% & & $\mathrm{OR}(95 \% \mathrm{Cl})$ & P.for.interaction \\
\hline Gender group & & & & & & $<0,001$ \\
\hline male & $\mathrm{TG} / \mathrm{HDL}$ & 4936 & $2164(43.8)$ & & $1.38(1.3 \sim 1.47)$ & \\
\hline Female & $\mathrm{TG} / \mathrm{HDL}$ & 5196 & $2158(41.5)$ & & $1.95(1.75 \sim 2.16)$ & \\
\hline Age group & & & & & & $<0,001$ \\
\hline$<30$ & $\mathrm{TG} / \mathrm{HDL}$ & 1994 & $683(34.3)$ & & $1.42(1.2 \sim 1.67)$ & \\
\hline$>=30,<40$ & $\mathrm{TG} / \mathrm{HDL}$ & 1608 & $590(36.7)$ & & $1.89(1.63 \sim 2.19)$ & \\
\hline$>=40,<50$ & $\mathrm{TG} / \mathrm{HDL}$ & 1594 & $703(44.1)$ & & $1.27(1.15 \sim 1.4)$ & \\
\hline$>=50,<60$ & $\mathrm{TG} / \mathrm{HDL}$ & 1626 & $758(46.6)$ & & $1.37(1.22 \sim 1.54)$ & \\
\hline$>=60,<70$ & $\mathrm{TG} / \mathrm{HDL}$ & 1709 & $846(49.5)$ & & $1.56(1.35 \sim 1.8)$ & \\
\hline$>=70$ & $\mathrm{TG} / \mathrm{HDL}$ & 1601 & $742(46.3)$ & & $2.85(2.32 \sim 3.52)$ & \\
\hline BMI group & & & & & & 0.017 \\
\hline$<18.5$ & $\mathrm{TG} / \mathrm{HDL}$ & 185 & $15(8.1)$ & & $1.6(0.41 \sim 6.2)$ & \\
\hline$>=18.5,<24$ & $\mathrm{TG} / \mathrm{HDL}$ & 2252 & $285(12.7)$ & & $1.96(1.62 \sim 2.36)$ & \\
\hline$>=24,<28$ & $\mathrm{TG} / \mathrm{HDL}$ & 2666 & $808(30.3)$ & & $1.5(1.36 \sim 1.65)$ & \\
\hline$>=28$ & $\mathrm{TG} / \mathrm{HDL}$ & 5029 & $3214(63.9)$ & & $1.46(1.35 \sim 1.57)$ & \\
\hline Diabetes group & & & & & & 0.01 \\
\hline No & $\mathrm{TG} / \mathrm{HDL}$ & 8519 & $3127(36.7)$ & & $1.45(1.36 \sim 1.53)$ & \\
\hline Yes & $\mathrm{TG} / \mathrm{HDL}$ & 1613 & $1195(74.1)$ & & $1.87(1.56 \sim 2.24)$ & \\
\hline Race group & & & & & & $<0,001$ \\
\hline Mexican American & $\mathrm{TG} / \mathrm{HDL}$ & 1407 & $734(52.2)$ & & $1.99(1.68 \sim 2.36)$ & \\
\hline Other Hispanics & $\mathrm{TG} / \mathrm{HDL}$ & 1077 & $519(48.2)$ & & $1.17(1.02 \sim 1.34)$ & \\
\hline Non-Hispanic white & $\mathrm{TG} / \mathrm{HDL}$ & 3809 & $1513(39.7)$ & & $1.49(1.37 \sim 1.62)$ & \\
\hline Non-Hispanic black & $\mathrm{TG} / \mathrm{HDL}$ & 2172 & $944(43.5)$ & & $2.05(1.71 \sim 2.45)$ & \\
\hline Other Race & $\mathrm{TG} / \mathrm{HDL}$ & 1667 & $612(36.7)$ & & $1.31(1.17 \sim 1.48)$ & \\
\hline Smoking group & & & & & & $<0,001$ \\
\hline No & $\mathrm{TG} / \mathrm{HDL}$ & 5896 & $2476(42)$ & & $1.81(1.66 \sim 1.98)$ & \\
\hline Yes & $\mathrm{TG} / \mathrm{HDL}$ & 4236 & $1846(43.6)$ & & $1.34(1.25 \sim 1.44)$ & \\
\hline Alcohol use & & & & & & $<0,001$ \\
\hline No & $\mathrm{TG} / \mathrm{HDL}$ & $6591 ?(65.1)$ & $2854 ?(43.3)$ & & $1.47(1.37 \sim 1.57)$ & \\
\hline Yes & $\mathrm{TG} / \mathrm{HDL}$ & $3541 ?(34.9)$ & $1727 ?(68)$ & & $1.88(1.67 \sim 2.12)$ & \\
\hline
\end{tabular}

Figure 3

Subgroup analysis based on the analysis of multi-factor logistic regression for the association between the TG/HDL ratio and IR.

https://ec.bioscientifica.com

https://doi.org/10.1530/EC-21-0414 (c) 2021 The authors Published by Bioscientifica Ltd

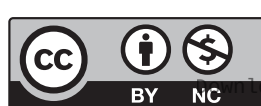

This work is licensed under a Creative Commons Attribution-NonCommercial 4.0 International License. ded from Bioscientifica.com at 04/26/2023 10:03:49AM via free access 
inflection point, the effect size and 95\% CI were 6.28 and 4.66-8.45, respectively. On the right side of the inflection point, the effect size and 95\% CI were 1.69 and 1.45-1.97, respectively (Table 5).

\section{Subgroup analyses}

We used age, gender, race, BMI, smoking, and diabetes as the stratification variables to study the trend of effect sizes in these variables (Fig. 3). Interactions were observed based on our a priori specification, including age, gender, BMI, smoking, and diabetes (all with $P$ values for interaction $<0.05$ ). In this study, a stronger association was detected for women, alcohol user, and diabetes patients compared with male and non-diabetes cases. In the age groups, the highest association was observed in group of older than 70s, the second strong level of the association was in the group of 30-40 years old, and the weakest association was in the 40-60 groups. Meanwhile, a weaker association was observed in the obese and smokers. It should also be noted that compared with Mexican and non-Hispanic Black Americans, other American races have a relatively weaker association between TG / HDL ratio and IR.

\section{Discussion}

Our results indicate that the TG/HDL ratio is positively associated with IR after adjusting for covariates. Notably, a nonlinear interaction between TG/HDL ratio and IR was discovered. The trend of the effect sizes for the left and right sides of the inflection point is not consistent (left: OR 6.28, 95\% CI 4.66-8.45; right: OR 1.69, 95\% CI 1.45-1.97). These results suggest an L curve for the independent association between the TG/HDL ratio and IR. Subgroup analysis will help us better understand the trend of the TG/HDL ratio and IR in atypical populations. This study found a stronger association in women, patients with diabetes, and those who consume alcohol. By contrast, a weaker association was detected in obese and smokers. In the age groups, the highest association was in old group ( $\geq 70$ years) and the second relationship was in the middle age group (Fig. 3). Compared with Mexican and non-Hispanic Black Americans, other American races have a relatively weaker association between TG/HDL ratio and IR.

Moriyama suggested that the TG/HDL-C ratio is linked to IR, components of metabolic syndrome (MetS), exercise, physical activity, and smoking, but lack of alcohol intake, in a sample of 1068 healthy Japanese subjects (36).
Similar findings were also reported by Sánchez-Escudero et al. (37) Rodríguez-Gutiérrez et al. (38), and He et al. (39) and consistent with the result of this study.

However, there are still important differences between the studies. Here, we elaborated the association between TG/HDL ratio and IR from different perspectives and in different subpopulations. We concluded that the association between TG/HDL ratio and IR gradually decreased with BMI, and the association was strongest in people with a BMI of 18.5-24. Moreover, we found the previous studies did not show a two-stage effect. The different results may be due to the following reasons: (1) the targeted population is different; (2) their studies did not analyze the relationship between the TG/HDL ratio and IR by curve fitting; and (3) these studies did not consider the effects of VD3, LDH, GGT, income, and education on the relationship between the TG/HDL ratio and IR when adjusting for covariates. However, these previous studies have confirmed the relationship of TG/HDL ratio and IR.

According to experimental studies, high TG/HDL ratio will lead to less retention of fatty acids, resulting in more fatty acids to be transported to the liver for TG synthesis, which become a vicious circle (40). TG-rich lipoproteins may accelerate the synthesis of factors including leptin, angiotensinogen, tumor necrosis factor $\alpha$, interleukin 6 , plasminogen activator inhibitor 1 , transforming growth factor B, adiponectin, adiponectin and resistin. These factors, at least in experimental level, are risk factors for insulin resistance or diabetes $(41,42,43,44)$.

The clinical value of this study can be summarized in the following two aspects: (1) to our best knowledge, this is the first report of an independent association between the TG/HDL ratio and IR in US adults, as well as the first report that shows age, BMI, and VD3 influence the relationship between TG/HDL ratio and IR in American adults; (2) the findings of this study will aid future research on the establishment of diagnostic or predictive models of IR.

The clinical value of this study can be summarized as follows: (1) as far as we know, our study sample is larger than previous samples; (2) we performed logistic regression curve fitting to analyze the relationship between the TG/ HDL ratio and IR; (3) the adjustment strategies in our study are better suited than those used in previous ones, and the results were more reliable after including VD3, LDH, and GGT as the adjusted variables; (4) we conducted a sensitivity analysis in this study; and (5) we conducted a subgroup analysis and discovered an interaction among gender, age, BMI, diabetes, race, smoking, and drinking.

Finally, there are also some limitations in the present study. (1) This study is based on American adults, which is 
a definite limitation for the universality and extrapolation of this research. (2) This study did not consider pregnant women, children, or people with specific medical conditions, so it is difficult to know whether the results of this study would apply to these populations. These limitations mainly come from the characteristics of NHANES database and do not affect the applicability of our results to the US adults. In this study, we have controlled the confounding factors to minimize the bias so as to make the results more credible.

\section{Declaration of interest}

The authors declare that there is no conflict of interest that could be perceived as prejudicing the impartiality of the research reported.

\section{Funding}

This work was supported by grants from National Natural Science Foundation of China (81860370, 32160233), General Project of Natural Science Foundation of Qinghai Province (2019-ZJ-970Q), CAS 'Light of West China' Program (2019), and Qinghai Scientific Innovation Project of Traditional Chinese-Tibetan Medicine (2020007).

\section{Ethics approval and consent to participate}

All data from the NHANES database have undergone ethical review, for details please see the NHANES website (https://www.cdc.gov/nchs/ nhanes/index.htm)

\section{Availability of data and materials}

Data can be downloaded from the 'NHANES' database (https://www.cdc. gov/nchs/nhanes/index.htm).

\section{Author contribution statement}

Rongpeng Gong and Gang Luo conceived the study; Rongpeng Gong wrote the manuscript; Mingxiang Wang, Shengnan Sun, and Lingbo Ma collected the data; Xiaoxing Wei read and revised the manuscript. All authors read and approved the final manuscript. Rongpeng Gong is the first author, Gang Luo is co-first author, Shengnan Sun and Xiaoxing Wei are the corresponding authors.

\section{References}

1 Lebovitz HE. Insulin resistance: definition and consequences. Experimental and Clinical Endocrinology and Diabetes 2001109 (Supplement 2) S135-S148. (https://doi.org/10.1055/s-2001-18576)

2 Abdul-Ghani MA \& DeFronzo RA. Pathogenesis of insulin resistance in skeletal muscle. Journal of Biomedicine and Biotechnology 20102010 476279. (https://doi.org/10.1155/2010/476279)

3 Yazıcı D \& Sezer H. Insulin resistance, obesity and lipotoxicity. Advances in Experimental Medicine and Biology 2017960 277-304. (https://doi.org/10.1007/978-3-319-48382-5_12)

4 Balakumar P, Maung-U K \& Jagadeesh G. Prevalence and prevention of cardiovascular disease and diabetes mellitus. Pharmacological Research 2016113 600-609. (https://doi.org/10.1016/j. phrs.2016.09.040)
5 Taylor R. Type 2 diabetes: etiology and reversibility. Diabetes Care 2013 36 1047-1055. (https://doi.org/10.2337/dc12-1805)

6 Rosenberg DE, Jabbour SA \& Goldstein BJ. Insulin resistance, diabetes and cardiovascular risk: approaches to treatment. Diabetes, Obesity and Metabolism 20057 642-653. (https://doi.org/10.1111/j.14631326.2004.00446.x)

7 Laakso M \& Kuusisto J. Insulin resistance and hyperglycaemia in cardiovascular disease development. Nature Reviews: Endocrinology 2014 10 293-302. (https://doi.org/10.1038/nrendo.2014.29)

8 Adeva-Andany MM, Martínez-Rodríguez J, González-Lucán M, Fernández-Fernández C \& Castro-Quintela E. Insulin resistance is a cardiovascular risk factor in humans. Diabetes and Metabolic Syndrome 201913 1449-1455. (https://doi.org/10.1016/j.dsx.2019.02.023)

9 Eckel RH, Grundy SM \& Zimmet PZ. The metabolic syndrome. Lancet 2005365 1415-1428. (https://doi.org/10.1016/S0140-6736(05)66378-7)

10 Lavie CJ, Ozemek C, Carbone S, Katzmarzyk PT \& Blair SN. Sedentary behavior, exercise, and cardiovascular health. Circulation Research 2019 124 799-815. (https://doi.org/10.1161/CIRCRESAHA.118.312669)

11 Pan K, Nelson RA, Wactawski-Wende J, Lee DJ, Manson JE, Aragaki AK, Mortimer JE, Phillips LS, Rohan T, Ho GYF, et al. Insulin resistance and cancer-specific and all-cause mortality in postmenopausal women: the women's health initiative. Journal of the National Cancer Institute 2020 112 170-178. (https://doi.org/10.1093/jnci/djz069)

12 Ju SY, Lee JY \& Kim DH. Association of metabolic syndrome and its components with all-cause and cardiovascular mortality in the elderly: a meta-analysis of prospective cohort studies. Medicine 201796 e8491. (https://doi.org/10.1097/MD.0000000000008491)

13 Welsh P, Preiss D, Lloyd SM, de Craen AJ, Jukema JW, Westendorp RG, Buckley BM, Kearney PM, Briggs A, Stott DJ, et al. Contrasting associations of insulin resistance with diabetes, cardiovascular disease and all-cause mortality in the elderly: PROSPER long-term follow-up. Diabetologia 201457 2513-2520. (https://doi.org/10.1007/s00125-0143383-9)

14 Bigazzi R, Bianchi S, Buoncristiani E \& Campese VM. Increased cardiovascular events in hypertensive patients with insulin resistance: a 13-year follow-up. Nutrition, Metabolism, and Cardiovascular Diseases 200818 314-319. (https://doi.org/10.1016/j.numecd.2006.11.001)

15 Perseghin G, Calori G, Lattuada G, Ragogna F, Dugnani E, Garancini MP, Crosignani P, Villa M, Bosi E, Ruotolo G, et al. Insulin resistance/hyperinsulinemia and cancer mortality: the Cremona study at the 15th year of follow-up. Acta Diabetologica 201249 421-428. (https://doi.org/10.1007/s00592-011-0361-2)

16 Peplies J, Börnhorst C, Günther K, Fraterman A, Russo P, Veidebaum T, Tornaritis M, De Henauw S, Marild S, Molnar D, et al. Longitudinal associations of lifestyle factors and weight status with insulin resistance (HOMA-IR) in preadolescent children: the large prospective cohort study IDEFICS. International Journal of Behavioral Nutrition and Physical Activity 201613 97. (https://doi.org/10.1186/s12966-0160424-4)

17 Gong R, Xu Z \& Wei X. The association between vitamin D3 and diabetes in both hyperuricemia and non-hyperuricemia populations. Endocrine 202174 90-99. (https://doi.org/10.1007/s12020-021-02778-y)

18 Muniyappa R, Lee S, Chen H \& Quon MJ. Current approaches for assessing insulin sensitivity and resistance in vivo: advantages, limitations, and appropriate usage. American Journal of Physiology: Endocrinology and Metabolism 2008294 E15-E26. (https://doi. org/10.1152/ajpendo.00645.2007)

19 DeFronzo RA, Tobin JD \& Andres R. Glucose clamp technique: a method for quantifying insulin secretion and resistance. American Journal of Physiology 1979237 E214-E223. (https://doi.org/10.1152/ ajpendo.1979.237.3.E214)

20 Keskin M, Kurtoglu S, Kendirci M, Atabek ME \& Yazici C. Homeostasis model assessment is more reliable than the fasting glucose/insulin ratio and quantitative insulin sensitivity check index for assessing insulin resistance among obese children and adolescents. Pediatrics 2005115 e500-e503. (https://doi.org/10.1542/peds.2004-1921)

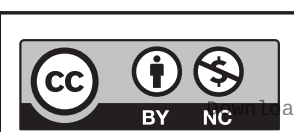

This work is licensed under a Creative Commons Attribution-NonCommercial 4.0 International License. ded from Bioscientifica com at 04/26/2023 10:03:49AM 
21 Lewis GF, Uffelman KD, Szeto LW \& Steiner G. Effects of acute hyperinsulinemia on VLDL triglyceride and VLDL apoB production in normal weight and obese individuals. Diabetes 199342 833-842. (https://doi.org/10.2337/diab.42.6.833)

22 Van Linthout S, Spillmann F, Schultheiss HP \& Tschöpe C. Highdensity lipoprotein at the interface of type 2 diabetes mellitus and cardiovascular disorders. Current Pharmaceutical Design 201016 1504-1516. (https://doi.org/10.2174/138161210791051031)

23 McLaughlin T, Abbasi F, Cheal K, Chu J, Lamendola C \& Reaven G. Use of metabolic markers to identify overweight individuals who are insulin resistant. Annals of Internal Medicine 2003139 802-809. (https://doi.org/10.7326/0003-4819-139-10-200311180-00007)

24 McLaughlin T, Reaven G, Abbasi F, Lamendola C, Saad M, Waters D, Simon J \& Krauss RM. Is there a simple way to identify insulin-resistant individuals at increased risk of cardiovascular disease? American Journal of Cardiology 200596 399-404. (https://doi.org/10.1016/j. amjcard.2005.03.085)

25 Krawczyk M, Rumińska M, Witkowska-Sędek E, Majcher A \& Pyrżak B. Usefulness of the triglycerides to high-density lipoprotein cholesterol ratio (TG/HDL-C) in prediction of metabolic syndrome in Polish obese children and adolescents. Acta Biochimica Polonica 201865 605-611. (https://doi.org/10.18388/abp.2018_2649)

26 Young KA, Maturu A, Lorenzo C, Langefeld CD, Wagenknecht LE, Chen YI, Taylor KD, Rotter JI, Norris JM \& Rasouli N. The triglyceride to high-density lipoprotein cholesterol (TG/HDL-C) ratio as a predictor of insulin resistance, $\beta$-cell function, and diabetes in Hispanics and African Americans. Journal of Diabetes and its Complications 201933 118-122. (https://doi.org/10.1016/j.jdiacomp.2018.10.018)

27 Johnson CL, Paulose-Ram R, Ogden CL, Carroll MD, KruszonMoran D, Dohrmann SM \& Curtin LR. National Health and Nutrition Examination Survey: analytic guidelines, 1999-2010. Vital and Health Statistics: Series 2, Data Evaluation and Methods Research 2013161 1-24.

28 Matthews DR, Hosker JP, Rudenski AS, Naylor BA, Treacher DF \& Turner RC. Homeostasis model assessment: insulin resistance and beta-cell function from fasting plasma glucose and insulin concentrations in man. Diabetologia 198528 412-419. (https://doi. org/10.1007/BF00280883)

29 Sumner AE \& Cowie CC. Ethnic differences in the ability of triglyceride levels to identify insulin resistance. Atherosclerosis 2008 196 696-703. (https://doi.org/10.1016/j.atherosclerosis.2006.12.018)

30 Voruganti VS, Lopez-Alvarenga JC, Nath SD, Rainwater DL, Bauer R, Cole SA, Maccluer JW, Blangero J \& Comuzzie AG. Genetics of variation in HOMA-IR and cardiovascular risk factors in MexicanAmericans. Journal of Molecular Medicine 200886 303-311. (https://doi. org/10.1007/s00109-007-0273-3)

31 Qu HQ, Li Q, Lu Y, Hanis CL, Fisher-Hoch SP \& McCormick JB. Ancestral effect on HOMA-IR levels quantitated in an American population of Mexican origin. Diabetes Care 201235 2591-2593. (https://doi.org/10.2337/dc12-0636)

32 Li Y, Pan A, Wang DD, Liu X, Dhana K, Franco OH, Kaptoge S, Di Angelantonio E, Stampfer M, Willett WC, et al. Impact of healthy lifestyle factors on life expectancies in the US population. Circulation 2018138 345-355. (https://doi.org/10.1161/ CIRCULATIONAHA.117.032047)

33 White GE, Mair C, Richardson GA, Courcoulas AP \& King WC. Alcohol use among U.S. adults by weight status and weight loss attempt: Nhanes, 2011-2016. American Journal of Preventive Medicine 201957 220-230. (https://doi.org/10.1016/j.amepre.2019.03.025)

34 Morris A. New test for diabetes insipidus. Nature Reviews: Endocrinology 201915 564-565. (https://doi.org/10.1038/s41574-019-0247-x)

35 Judd E \& Calhoun DA. Apparent and true resistant hypertension: definition, prevalence and outcomes. Journal of Human Hypertension 201428 463-468. (https://doi.org/10.1038/jhh.2013.140)

36 Moriyama K. Associations between the triglyceride to high-density lipoprotein cholesterol ratio and metabolic syndrome, insulin resistance, and lifestyle habits in healthy Japanese. Metabolic Syndrome and Related Disorders 202018 260-266. (https://doi.org/10.1089/ met.2019.0123)

37 Sánchez-Escudero V, García Lacalle C, González Vergaz A, Remedios Mateo L \& Marqués Cabrero A. The triglyceride/glucose index as an insulin resistance marker in the pediatric population and its relation to eating habits and physical activity. Endocrinología, Diabetes y Nutrición 202168 296-303. (https://doi.org/10.1016/j. endien.2020.08.015)

38 Rodríguez-Gutiérrez N, Vanoye Tamez M, Vázquez-Garza E, Villarreal-Calderón JR, Castillo EC, Laresgoiti-Servitje E, ElizondoMontemayor L \& García-Rivas G. Association of the triglyceride/ high-density lipoprotein cholesterol index with insulin resistance in a pediatric population in Northeast Mexico. Metabolic Syndrome and Related Disorders 202018 333-340. (https://doi.org/10.1089/ met.2020.0046)

39 He J, He S, Liu K, Wang Y, Shi D \& Chen X. The TG/HDL-C ratio might be a surrogate for insulin resistance in Chinese nonobese women. International Journal of Endocrinology 20142014 105168. (https://doi. org/10.1155/2014/105168)

40 Yeh WC, Tsao YC, Li WC, Tzeng IS, Chen LS \& Chen JY. Elevated triglyceride-to-HDL cholesterol ratio is an indicator for insulin resistance in middle-aged and elderly Taiwanese population: a crosssectional study. Lipids in Health and Disease 201918 176. (https://doi. org/10.1186/s12944-019-1123-3)

41 Haluzík M, Parízková J \& Haluzík MM. Adiponectin and its role in the obesity-induced insulin resistance and related complications. Physiological Research 200453 123-129.

42 Bełtowski J. Adiponectin and resistin - new hormones of white adipose tissue. Medical Science Monitor 20039 RA55-RA61.

43 Morton RE. Cholesteryl ester transfer protein and its plasma regulator: lipid transfer inhibitor protein. Current Opinion in Lipidology 199910 321-327. (https://doi.org/10.1097/00041433-199908000-00006)

44 Kolovou GD, Anagnostopoulou KK \& Cokkinos DV. Pathophysiology of dyslipidaemia in the metabolic syndrome. Postgraduate Medical Journal 200581 358-366. (https://doi.org/10.1136/ pgmj.2004.025601)

Received in final form 14 October 2021

Accepted 22 October 2021

Accepted Manuscript published online 22 October 2021 https://ec.bioscientifica.com https://doi.org/10.1530/EC-21-0414 (c) 2021 The authors Published by Bioscientifica Ltd

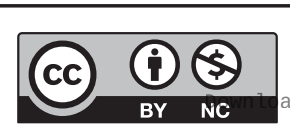

This work is licensed under a Creative Commons Attribution-NonCommercial 4.0 International License. ded from Bioscientifica com at 04/26/2023 10:03:49AM 